Vol. XXVIII - REVISTA DE HISTORIA - Ano XV

\title{
CONFERENCIAS
}

\author{
ZACHARIAS WAGENER E O SEU \\ "THIERBUCH" ( $\left.{ }^{\star}\right)$.
}

A hostilidade existente entre a Espanha, sob cujo domínio caira o Brasil a partir de 1580, com a extinção da dinastia de Aviz reinante em Portugal, e a Holanda, antes subjugada por aquela grande potência européia do século XVI, foi o motivo e o pretexto para que poderosas emprêsas comerciais, instaladas nos Países-Baixos, voltassem suas vistas para as riquezas desta banda do Atlântico, cobiçando-as e tratando de alcançá-las a ferro e a fogo.

Iniciada essa ação predatória contra a primitiva metrópole do Brasil-Colonial, ou seja, a Cidade do Salvador, em fins do século XVI, com a vistosa expedição de Pieter van der Does, que dos portos das Flandres zarpara à testa de setenta barcos de guerra rumo às nossas plagas, sendo desbaratada essa frota em grande parte nas costas da Africa pela febre amarela e ficando reduzido apenas a sete navios o contingente que chegou até a Bahia, em dezembro de 1599 , nada conseguindo de eficiente; e prosseguida mediante posteriores ataques à capital baiana por flibusteiros neerlandeses, entre outros, Paulus var Caarden, em 1604, sem maior êxito, tiveram, contudo, melhor sorte as armas flamengas, após a instituição, em 1621, da célebre Companhia das Indias Ocidentais, na cidade de Amsterdão. Bem sucedidos, a princípio, em sua investida de 1624 contra a cidade da Bahia, que foi ocupada sem maior resistência, a 10 de maio daquele milésimo, por poderosa esquadra comandada pelo almirante Jacob Willekens, secundado pelo famoso e bravo Pieter Heyn, apelidado com justa razão o "Terror dos Mares", dadas sua coragem e capacidade bélica, sofreram os

(*). - Conferência pronunciada no Curso de Arte Colonial Brasileira, promovido pela Comissão Municipal de Cultura de Santos, em 3 de maio de 1963. 
holandeses o seu primeiro grande revés com a perda da magnífica prêsa um ano após a conquista.

Persistentes e destemidos, voltaram de nôvo os batavos ao assalto, em 1630, lançando-se contra a Capitania de Pernambuco, a Nova Lusitânia de Duarte Coelho, então a mais próspera de tôdas as colônias do Brasil, graças à florescente indústria açucareira, e nela conseguiram instalar-se por período assás longo, ou seja, de 1630 a 1654 .

Firmado o pé, de início, em Olinda e Recife, estendeu-se gradativamente o domínio holandês a uma grande área do Nordeste do Brasil, mediante repetidos reforços chegados dos Estados Gerais.

Numa dessas expedições, precisamente a 18 de julho de 1634, embarcou com destino a Recife, como simples soldado, certo jovem alemão, natural da cidade de Dresden, na Saxônia, e amante de aventuras. Filho de um juiz e diretor de assuntos religiosos em sua terra natal, aquêle môço, que se chamava Zacharias Wagener, com vinte anos incompletos, fôra ter antes a Amsterdão, à cata de melhor ganho de vida. Empregara-se, a princípio, na casa do famoso editor de mapas da época, o livreiro Wilhelm Janson Blau. Aproveitando a grande aptidão inata do jovem saxão para o desenho, incumbira-o Blau de traçar cartas geográficas. Nio fim de um ano, porém, cansado da vida sedentária que levava, e aconselhado pelo seu próprio patrão, decidiu Wagener engajar-se numa frota rumo ao Brasil. Dessa forma chegou êle a Recife dezesseis semanas após a data supra-indicada. Indo servir na fortaleza "Ernestus", sob as ordens do major Bajarts, logo deixou o serviço ativo das armas, sendo aproveitado, pela sua boa caligrafia, como escrivão da companhia em que fôra lotado. Durante três anos exerceu essas modestas funções, a inteiro contento. Em 1637, ao empossar-se no cargo de Governador Geral do Brasil-Holandês, o conde João Maurício de Nassau-Siegen, foi chamado Wagener para desempenhar o ofício de "escrivão doméstico" (secretário particular) de S. Exa., encarregando-se de prover as necessidades habituais do paço daquele governante. Nassau, como é do conhecimento geral, fizera-se acompanhar, em sua viagem para o Brasil, duma plêiade de artistas e cientistas, além de poderosos contingentes militares. Nobre, de elevada educação, ao lado do aproveitamento das riquezas do solo brasileiro, tratou de investigar a fundo a fauna e a flora de nosso país, incumbindo dessa missão o famoso naturalista Jorge Marcgrave e o físico (médico) Guilherme 
Piso. Ao construir, na ilha de Antônio Vaz, o célebre palácio residencial de Friburgo, cercou-o de jardins, onde fêz cultivar as principais plantas indígenas, e nos quais conseguiu reunir grande número de animais silvestres, a fim de melhor poderem ser observados por aquêles cientistas.

$\mathrm{Na}$ qualidade de residente na côrte de Nassau, entrou Wagener a interessar-se igualmente pelos elementos nativos que o rodeavam e, aproveitando os momentos de folga, passou a desenhá-los sem maiores pretensões, com a finalidade apenas de transmitir aos seus conterrâneos europeus conhecimentos exatos sôbre a natureza do Brasil, inteiramente deformada por narrativas fantásticas enviadas para o Vielho Mundo, pelos primeiros visitantes de nossas plagas. Em fôlhas de papel aproximadamente de formato $37 \times 22 \mathrm{cms}$., pintou a aquarela, copiando-os do natural, quase todos os animais que viviam em nossos campos e matas e no seio de nossas águas costeiras, desde os peixes às aves e aos mamíferos, e bem assim os répteis e os insetos, passando pelos moluscos e crustáceos. Por outro lado, teve igual procedimento em relação às nossas frutas e plantas, sobretudo as utilizadas para fins de alimentação. Finalmente, observando os habitantes pertencentes às três raças que aqui se caldearam, desenhou os tipos clássicos de tôdas elas, inclusive algumas cenas características de seus costumes e usanças.

No ano de 1641, apertaram as saudades dos pais e da terra natal. Solicitou então Wagener dispensa dos seus serviços a Nassau e voltou para a Europa, numa época bastante agitada como foi o período derradeiro da Guerra dos Trinta Anos (1618-1648). Com muita dificuldade conseguiu atravessar a Alemanha, conflagrada pela luta entre príncipes católicos e protestantes, e chegar a Dresden. Logo, porém, a vida pacata que levavam os habitantes dessa cidade entediou-o, fazendo-o regressar à Holanda. De Amsterdão partiu para o ExtremoOriente, já então como funcionário da Companhia das Índias Orientais, no ano de 1642. Aventureiro dotado de grande firmeza de vontade e de qualidades outras muito apreciadas, subiu ràpidamente de posição em Batávia, capital da ilha de Java. Empregado a princípio como desenhista de cartas marítimas, passou em seguida a postos cada vez mais importantes e melhor remunerados, ocupando cargos de relêvo na administração, chefiando embaixadas a países do Oriente, como a China e o Japão, sendo por último nomeado Governador da Colônia do Cabo, na Africa do Sul, depois de haver sido ar- 
quiteto-mor de tôda a India Holandesa. Após mais de 25 anos de bons serviços prestados à Companhia das Indias Orientais, requereu aposentadoria, que lhe foi concedida, voltando à Holanda com grandes honras militares, na qualidade de vice-almirante, a comandar uma das naus da frota em que regressou. Infelizmente, sua combalida saúde não permitiu que sobrevivesse muito tempo, vindo a falecer meses depois de chegar a Amsterdão, no ano de 1668.

A partida para as Indias Orientais e a longa estada em tão distantes plagas, afastaram de Wagener por completo o interêsse que manifestou, de início, pelas coisas do Brasil, e os seus cadernos de desenhos, acrescidos de preciosos apontamentos sôbre os objetos e assuntos representados, bem como um extrato do diário auto-biográfico de suas viagens, foram parar muito mais tarde nos arquivos de sua cidade natal.

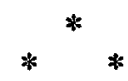

\section{O "THIERBUCH"}

No ano de 1888, ao completar o vigésimo quinto aniversário de fundação a Sociedade Geográfica de Dresden, foi publicado para comemorá-lo, nessa cidade, interessante livro jubilar, intitulado "Festschrift zur Jubelfeier des 25jährigen Bestehens des Vereins für Erdkunde zu Dresden". Entre os principais colaboradores dêsse memorial figura o Dr. Paul Emil Richter, que nêle inseriu, da pág. 59 à pág. 91, dois inéditos preciosíssimos, recolhidos ao Real Gabinete de Gravuras de Cobre da Capital da Saxônia, havia mais de 200 anos (1), e totalmente ignorados dos estudiosos até então. Obedeciam semelhantes publicações aos seguintes e compridos títulos: "Kurtze Beschreibung der 35-jährigen Reisen und Verrichtungen, welche Weyland Herr Zacharias Wagner in Europa, Asia, Africa und America, meistentheils zu Dienst der Ost- und WestIndianischen Compagnie in Holland, rühmlichs gethan und abgeleget, gezogen aus des seelig gehaltenen eigenhändigen Journal" (págs. 59-78) e "Thier Buch Darinnen viel unterschiedene Arter der Fische vögel vierfüssigen Thliere Gewürm, Erd- und Baumfrüchte, so hin undt wieder in Brasilischen bezirck, undt

(1). - Segundo informaçāo obtida diretamente de Dresden, tais inéditos achamse relacionados no mais antigo catálogo dessa instituição, a datar de 1738, elaborado pelo Sr. Heucher. 
gebiethe, Der Westindischen Compagnie zu schauwen undt anzutreffen, undt daher in den Teutzschen Landen fremde undt unbekandt. Auffs genawest mit seinen Natürlichen Farben, samt behörlichen Nahmen, wie auch kurtzer untengesetzter beschreibung, Abgebildet sindt. Alles selbst augenscheinlich zu lust undt gefallen Denen sonst newbegierigen Gemühtern, bezeignet. In Brasilien Unter der hochlöblichen Regierung, des hochgebohrnen Herrn Johan Moritz Graffen von Nassau ete. Gubernator Capitain undt Admiral General von Zacharias Wagenern von Dresden" (págs. 79-91) (2). O primeiro trabalho nada mais é do que o extrato na íntegra da auto-biografia retro referida. No segundo, Richter, depois de rápidas explanações sôbre a magnífica coleção dos 109 (3) desenhos que o compõem, transcreve os textos de tôda a parte final, a contar da figura 93, aí compreendido o precioso acervo etnográfico da obra. Infelizmente, ao que pude verificar, não ilustrou Richter sua publicação com nenhum dos desenhos de Wagener.

Aberta a picada inicial, com essa primeira divulgação retro-exposta, surgiram em diferentes lugares, sobretudo na Alemanha, estudos sôbre o autor do "Thierbuch" já famoso. No espaço dos três quartos de século decorridos de então para cá, avulta interessante bibliografia a respeito dêle, principalmente européia. No Brasil, o pioneiro em tal sentido veio a ser Alfredo de Carvalho, insigne historiador, que, em 1903, traduziu e estampou na "Revista do Instituto Arqueológico Pernambucano" (vol. XI, n. ${ }^{\circ} 60$, dezembro de 1903, págs. 181-195, Recife, 1904) a publicação de Richter na parte que se refere ao nosso país, dando-lhe o título de "O Zoobiblion de Zacharias Wagener", e tecendo em derredor do mesmo oportunos

(2). - Em português, respectivamente: "Breve descrição das viagens e funções que, principalmente a serviço das Companhias Holandesas das fndias Orientais e Ocidentais, gloriosamente realizou e exerceu, por espaço de 35 anos, o falecido Sr. Zacharias Wagener, na Europa, Ásía, Africa e América, extraída do próprio diário autógrafo do finado". (Págs. 59-78), e "Livro de animais no qual se contêm muitas diferentes espécies de peixes, pássaros, quadrúpedes, vermes, frutas e raízes que se encontram e observam na terra do Brasil, sujeita ao dominio da Companhia das índias Ocidentais, e por isso estranhas e desconhecidas na Alemanha. Representadas com a máxima exatidão, com as suas côres naturais, nomę próprios e breves descrições marginais. Tudo desenhado vistosamente para gaúdio e satisfação dos espiritos curiosos, no Brasil, sob o Louvabilíssimo Govêrno do Muito Nobre Senhor Joāo Maurício, Conde de Nassau, etc., Governador e Almirante General, por Zacharias Wagener, de Dresden", (págs. 79-91).

(3). - Na realidade 110. Contou-os mal Richter, e todos os que lhe seguiram as pegadas incidiram no mesmo engano. 
comentários. Igualmente na capital de Pernambuco, no N. ${ }^{\circ} 1$ dos "Arquivos" da Prefeitura Municipal do Recife, março de 1942, págs. 99-111, foi inserta a versão portuguêsa de importante artigo escrito e publicado em Berlin, por $\mathrm{O}$. Quelle, no ano de 1936, sob a epígrafe "Zacharias Wagener e sua obra no Brasil", acompanhada da reprodução de certo número de gravuras, inclusive de alguns animais. Recentemente, o Prof. E. Schaeffer, de São Paulo, obteve autorização do "Kupferstich Kabinett" de Dresden, para publicar em nosso meio tôda a obra de Wagener, da qual lhe foi cedida cópia integral em microfilmes. Por sua vez, depois de escrever um artigo sôbre o assunto na revista Anhembi, n. ${ }^{\circ} 127$, junho de 1961, págs. 212224, transferiu-me gentilmente o Prof. Schaeffer essa permissão, com o respectivo material, que constituirá o IV volume de minha série "Brasiliensia Documenta", já em elaboração 'gráfica bastante adiantada.

Compõe-se o "Thierbuch" ou "Zoobiblion" (versão proposta por Alfredo de Carvalho, desivada da língua grega, a significar "Livro de Animais") de 110 esplêndidos desenhos, em sua quase totalidade coloridos a aquarela, dos quais 73 de animais, 19 de frutas e raízes, e os 18 restantes a abrangerem tipos etnográficos, com algumas de suas usanças, um engenho de açúcar, o mercado de escravos, uma das residências de Nassau na cidade Maurícia e três plantas (dois cortes de casas de fazer açúcar e o traçado geográfico da cidade nassoviana). De todo êsse conjunto tem sido divulgada, em diferentes publicações, apenas a parte final acima referida. Os animais e as frutas, salvo raríssimas exceções, permanecem até o momento inteiramente inéditos. Cada figura, onde aparecem às vêzes mais de um elemento, é acompanhada duma legenda manuscrita em alemão setecentista, redigida pelo próprio punho do Autor, na qual se inserem curiosos dados por êle colhidos da voz corrente do povo acêrca dos assuntos representados, acrescidos de algumas de suas observações pessoais. Neste particular, parecem ser absolutamente fidedignas, visto como os informes que reproduzem, embora sem preocupações eruditas, combinam em muito boa parte com a realidade.

Wagener não era um profissional da paleta, não obstante dotado de talento artístico notável. Outrossim, não fêz parte do séquito de artistas que acompanhou o conde Maurício ao Brasil. Como vimos, já se encontrava no Recife por ocasião do advento dêsse Governador-General, em 1637. A despeito de ha- 
ver-se agregado à administração superintendida por Nassau durante quatro anos, não agiu como "artista oficial", tanto assim que se retirou para a Europa três anos antes dêle. A' meu ver, não deve ser incluído entre os "seis pintores" que estiveram a serviço do Conde e por êle mencionados em sua célebre carta a Luís XIV, rei de França, em que pesem abalizadas opiniões em contrário. Consoante êle próprio declarou no prefácio que chegou a redigir, evidentemente com o propósito de dar publicidade a seu trabalho, constituia sua intenção apenas reunir documentação exata sôbre as coisas do Brasil, a fim de apresentá-las aos seus compatriotas europeus. Humilde reposteiro da Côrte da Mauricéia, vinha de longa data desenhando tudo quanto lhe traziam os indígenas para modêlo. Nas notas que redigiu para ilustrar suas composições plásticas, refere-se mais de uma vez a isso. Trabalhou sobretudo com absoluta honestidade, preferindo deixar incompletos certos desenhos, a fantasiar coisas inexistentes. Assim, declarou em relação a um cágado d'água, do qual the forneceram simplesmente a carapaça, por êle reproduzida sem os pés e sem a cabeça: "Trouxeram-me certa vez para desenhar o casco de um bonito cágado; mas eu nunca pude saber como eram a cabeça e os pés". De outra feita, deixou também incompleto o desenho de um siri, por não poder suportar o mau cheiro que exalava e haver sido obrigado por isso a jogá-lo fora, fazendo semelhante declaração na legenda correspondente. Talvez tenha tido ensejo de observar alguns dos animais reunidos no jardim zoológico do palácio da ilha de Antônio Vaz. Mas, se o fêz, foi por curto prazo, visto como se retirou de lá pouco depois de terminada aquela construção, por volta de 1639 .

Em alentada obra que publicou no ano de 1938, em Copenhague, sôbre Albert Eckhout, pintor de elevado mérito, companheiro de Frans Post na "Missão Nassau", encarregado de reproduzir motivos zoológicos, botânicos e etnográficos, cotejou Thomas Thomsen diversos quadros dêsse artista com alguns desenhos de Wagener, absolutamente idênticos entre si, deduzindo daí que êste último se valeu no caso dos mesmos esboços traçados por aquêle outro pintor, o que representa de certo modo plágio. Já intrigara essa semelhança a outro analista que tratara do assunto muitos anos antes, ou seja, Paul Ehrenreich. Em artigo escrito e publicado na revista "Globus" (Braunschweig, 1894, vol. LXVI, págs. 81-90), sob o título original "Über einige ältere Bildnisse süd-amerikanischér Indianer", traduzido por Oliveira Lima e inserido na "Revista do 
Instituto Arqueológico Pernambucano", vol. XII, n. ${ }^{\circ}$ 65, junho de 1905, págs. 18-46, Recife, 1907, Ehrenreich se manifesta a princípio a favor de Wagener, como tendo prioridade sôbre Eckhout nos desenhos, baseando-se no fato de haver êle regressado para a Auropa em 1641, ano a partir do qual se acham datados os trabalhos etnográficos dêste último, recolhidos ao museu da capital da Dinamarca. Todavia, linhas adiante, passa a admitir Ehrenreich que ambos se valeram da mesma fonte de esboços, traçados anteriormente, sem especificar por qual dos dois organizada. Kurt Nimuendaju, êsse famoso etnólogo alemão que viveu à moda selvagem entre os indígenas do Norte do Brasil durante boa fase de sua existência, casando-se com uma índia, autoridade, portanto, em tais assuntos, apreciando a semelhança dos desenhos em aprêço, notou certo pormenor que os distingue, muito curioso. Assim, ao ser figurado um tapuia com as setas apoiadas no ombro, desenhou Wagener as pontas das mesmas voltadas para a frente e para baixo, exatamente como as carregam os índios da região, ao passo que Eckhout colocou as referidas pontas para cima e para trás, à maneira dos soldados europeus conduzirem suas armas. Isso foi o suficiente para deduzir Nimuendaju que Wagener teve diante dos olhos, ao executar seu desenho, o modêlo original, sendo pouco provável que o houvesse copiado dum esbôço incorreto, como é a figura traçada por Eckhout. De pleno acôrdo com essa dedução lógica estou eu por minha vez: ninguém copia certo uma coisa errada.

A sequiência em que se encontram atualmente as fôlhas do "Thierbuch" não é provável que tenha sido a primeira estabelecida por Wagener. Sofreu evidentemente o trabalho muitas manipulações no decorrer de mais de três séculos de existência e com isso profundas mudanças na paginação. Constituem os desenhos de animais e frutas do Brasil que compõem a coleção, os primeiros que se fizeram rigorosamente, no mundo, sôbre tais coisas brasileiras. Representam preciosa fonte de informação acêrca do que já existia entre nós há mais de trezentos anos. Uma particularidade despertou-me a atenção. Entre as frutas comuns representadas (banana, goiaba, abacaxi, mamão, laranja, maracujá, etc.) não aparece a manga, de que é tão rica, no presente, a região pernambucana, com variedades apreciadíssimas, verbi gratia a chamada Itamaracá, verdadeiro favo de mel. Não teria contemplado Wagener uma vez sequer uma mangueira? Ou não as havia ainda em profusão na épo- 
ca? A resposta a estas interrogações foi-me dada por um conhecedor do assunto, o agrônomo Armando Martins Clemente, que me assegurou só ter sido introduzida a cultura da manga no Brasil muito tempo depois das invasões holandesas.

Santos, abril de 1963.

EDGARD DE CERQUEIRA FALCÃO

do Instituto Histórico e Geográfico de Santos 